\title{
JET Decision Taken
}

The Research Council of the European Communities has finally come to a decision on the site for the Joint European Torus, western Europe's projected Tokamak reactor (Europhysics News, 6, 4 p. 6; 8, 7/8, p. 3). After more than two years of argument the project was first presented to the Council on July 18,1975 - the U.K. site at Culham, alongside the Atomic Energy Authority's fusion laboratory has been selected. A codicil to the agreement is that should a second machine be built as a follow-up to JET 1 , all sites within the Community outside the U.K. will be eligible for consideration. So ends the long argument on where it will be built.

In October of last year it had been agreed that the project would be run as a "joint enterprise". Although the conception of such organizations was written into the original Euratom agreement, this will in fact be the first to be set up within the Community although some existing national projects have in the past been denominated as such. For JET it means a new European organization with its own particular structure responsible to the participating bodies viz. Euratom, contributing $80 \%$, the UK as host state, $10 \%$, and a group of associated institutions which have been collaborating through various national laboratories in the joint fusion programme, also $10 \%$. This fraction will be contributed by the institutions on a scale that is proportional to the past annual budgets of the relevant laboratories.

A Provisional Council has been set up under the presidency of Professor Jean Teillac, Haut Commissaire of the French Commissariat à l'Energie Atomique, with the mandate to appoint a provisional project leader and, within four months, present to the Council of the Community, unanimous proposals for the statutes of the new organization and its head-quarters agreement with the host state.

For the construction period which is scheduled to last five years, a budget of $150 \mathrm{M} \mathrm{U} / \mathrm{A}$ (roughly $350 \mathrm{M}$. Sw. Fr.) has been agreed. As this runs two years into the next 5-year planning period of the Community it will be necessary to obtain again unanimous approval for the second instalment, but no difficulty is anticipated in this respect. The Community's annual budgets (which incidentally are ap- proved on a majority vote) currently include about $100 \mathrm{M} \mathrm{U} / \mathrm{A}$ for fusion research. No undertaking has yet been given as to the length of time that JET will operate but a period of seven to eight years has been indicated. The staff will number about 320 scientific and 120 technical people recruited from the countries of the Community.

Everywhere in the Comunity the long delay in coming to an agreement has been deplored, but not so much from the point of view that this has compromised the continuity of the research and design effort led by Paul Rebut since 1973, but in the context of some imaginary race against the United States and Soviet Union. In the scientific community, while a healthy spirit of rivalry prevails, people are only too well aware that only by a concerted effort at the full international level will thermonuclear fusion become a practicable energy source.

Relative size of the main fusion devices which are at present in operation, under construction or at the design stage throughout the world, as recorded in the report published on The JET Project by the Commission of the European Communities. Of those cited, TFR is in France, The Frascati Tokamak is in Italy, DITE and now JET are in the U.K., T-10 is in the U.S.S.R. and the rest are in the U.S.A. The dimensions are to scale and the plasma current and magnetic field are shown alongside, together with the date of operation; that given for JET must be considered to be optimistic by more than one year.

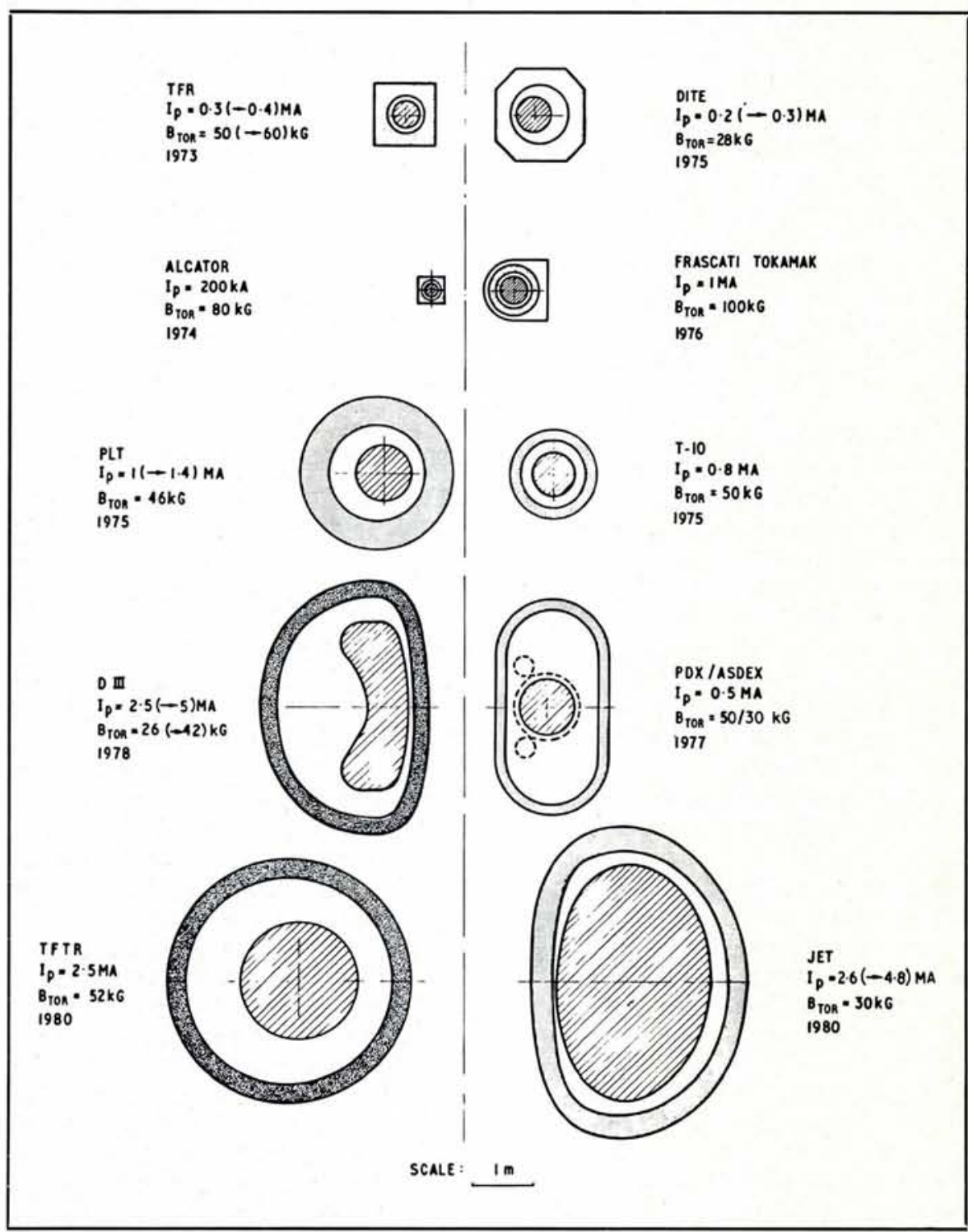

